\title{
Standardization and Innovation Management
}

\author{
Isabel Caetano $^{1}$ \\ ${ }^{1}$ President of the Portuguese Technical Committee \\ for Research \& Development and Innovation Activities, Portugal \\ President of CT 169, IPQ, Portugal; COTEC Portugal and INDEG - ISCTE Executive \\ Education \\ isabel.caetano@cotec.pt, isabel.caetanodiscte.pt
}

\section{Letter from Standardization}

\begin{abstract}
Innovation management enables organizations to focus on competitiveness and successful performance. Standardization can enhance organizational capabilities in order to be aligned with national and international best practices as well as to develop internal competences, routines and processes that can leverage an innovation journey towards excellence. At national and international levels, evidence demonstrates the importance of standardization, as a body of knowledge, to contribute to business innovation and to increase competitiveness and realization of value.
\end{abstract}

Keywords. Standardization, Innovation Management, Measurement, Evaluation, Assessment.

\section{Introduction}

As a voluntary process, standardization is recognized as a potential driver for innovation. Several studies highlighted that it can help companies to demonstrate their innovative products features and to increase business value creation (Swann, 2010).

Also, through common and harmonized rules and guidelines, resulting from consensus among stakeholders, organizations can identify relevant innovation factors influencing its present and future performance as well as align its processes according to best practices, continuous improvement and standard requirements.

As in other domains, a controversial question that arises frequently is: "is standardization an innovation enabler or an innovation barrier?"

An answer to this crucial debate is not simple. Different types of standards can produce distinctive effects depending also from several factors, as dimension, technological intensity, culture and strategy, just to mention a few, influencing its adoption. Nevertheless, standardization diffuses knowledge, increases predictability, thus reducing uncertainty and risk, and facilitates state of the art dissemination to companies, benefiting SMEs.

The national and international frameworks already developed to harmonize innovation management reaffirm that standardization can leverage firms' capabilities to absorb, apply and transform knowledge into value creation. 
Context and institutions matter. Their influence, through standards, enables innovation actors to guide its action and to easily identify and develop innovation enablers, processes and best practices.

\section{Framework at national level - The case of Portugal}

Since 2007, Portugal has launched several standards aiming to harmonize a common approach to innovation management concepts, processes, including innovation projects management, innovation assessment and innovation systems .

The Portuguese Standard NP 4457:2007 "Management of Research, Development and Innovation (RDI), RDI Management System Requirements" was based on an innovation conceptual model (Caraça et al, 2009) aimed to update business innovation management frameworks, still generally focused at a linear perspective of the innovation process, thus benefitting from an open innovation approach and from a broader definition of innovation (OECD, 2005).

From academic and practioners perspectives, studies have been developed, revealing that companies that implemented innovation management systems (IMS), according to the Portuguese standards, recognized its impact in different areas, including knowledge management, communication and networking, engagement and participation, project management, creativity stimulation and ideas management, new product development or reputation and internationalization.

During the first years of standards adoption by organizations operating in Portugal, results demonstrate that main benefits were identified (Table 1) and summarized in a guide that provided valuable information for other companies aiming to follow the same path (COTEC Portugal, 2010).

Table 1. Innovation Management Systems Standardization: Main Benefits

Main Benefits of Innovation Management Standardization in Portugal

Information (data consolidation about projects, practices, etc.)

Management improvement

Internal communication and debate on innovation

Stimulus of Innovation culture

Knowledge management

Adoption of tools and methods focusing innovation based value creation

Creativity and ideas generation

Source: Best Practices Guide in Innovation Management (Original: "Guia de Boas Práticas de Gestão de Inovação"), COTEC Portugal, 2010

Apart from the main benefits highlighted above, some other advantages were indicated, 
in spite of being less referred by the 24 companies surveyed in 2010 , and included top management involvement, innovation productivity increase, better and more efficient solutions for clients and for the organization, easy access to tax incentives and financing and finally workplace innovation.

Also, companies adopting innovation management standards aim to reinforce their internal capabilities, one of the reasons explaining why it is possible to find companies from different sizes, sector or maturity profiles under this movement.

Nevertheless, firms recognized some difficulties that cannot be neglected. The degree of novelty from the standards and the need to understand the underlying concepts were identified as obstacles to the implementation and certification of innovation management systems. Also, the absence of innovation management methodologies and tools sufficiently disseminated, including innovation projects and open innovation management, creativity and ideas management, evaluation of results and improvement as well as performance assessment, was considered as a weakness in many organizations.

\section{Framework at international level}

At international level, firstly at CEN - European Committee for Standardization (www.cen.eu) and nowadays also in ISO - International Standardization Organization (www.iso.org), innovation is considered as a priority topic for standardization, not only as a complementary domain to integrated management systems but also as a specific domain covering a broad spectrum of its activities.

Since November 2008, standardization documents were produced aiming to provide a systematic approach to innovation, complementing national initiatives, developed in Spain, Portugal, France and other European countries. Spain as a pioneering country in the innovation management standardization chaired CEN Technical Committee 389 "Innovation Management".

The main objective of the CEN "Family" of Technical Specifications (TS) is to guide European organizations to be aware and to develop innovation as a driver for competitiveness and value creation.

A brief summary of the seven TS can highlight its relevance for a systematic approach:

CEN/TS 16555-1:2013, Innovation Management System: This Technical Specification aims to present a framework, integrating activities crucial to generate innovations as a "routine" process and to target specific innovation determinants that include Organization Context, Leadership, Planning, Innovation Enablers, Innovation Process and Results, Innovation Management Techniques and Innovation, Performance assessment, briefly represented in the following conceptual model: 


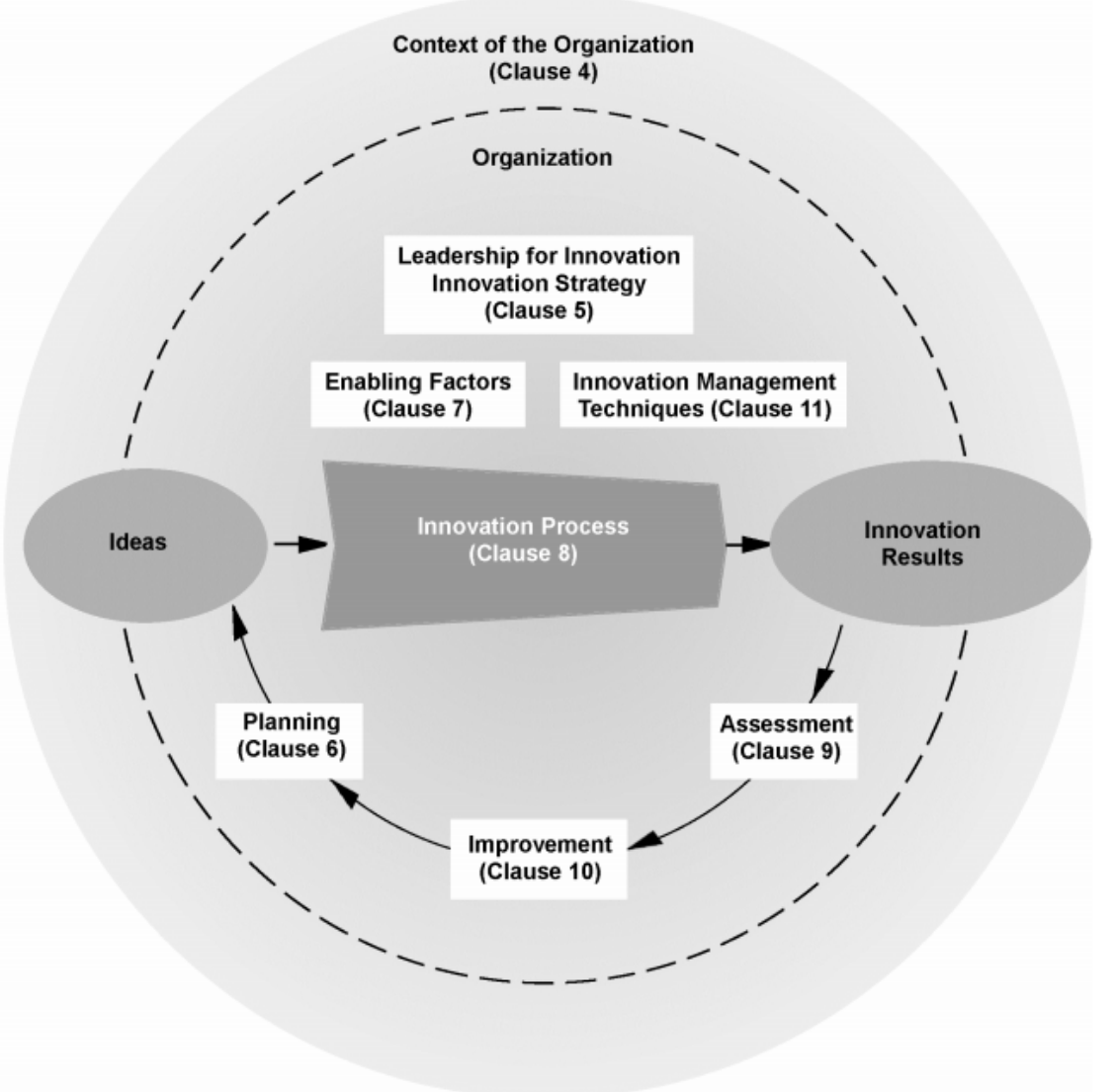

Fig. 1. Innovation Management System Elements.

Source: CEN. (2013). CEN/TS 16555-1:2013 "Innovation Management - Part 1: Innovation Management System", Figure 1 "Key elements covered by this Innovation Management System", European Committee for Standardization (CEN).

CEN/TS 16555-2:2014, Strategic intelligence management: As innovation management depends on organizational capabilities to translate strategic signals and emerging trends into valuable inputs to innovation strategy and projects, this TS can be used to ensure intelligence and foresight can support innovation management.

CEN/TS 16555-3:2014, Innovation Thinking: Based on a structured approach, that can be complemented by other methods and tools to promote innovation, Innovation Thinking aims to capture information, insights and experiences to maximize opportunities and problem solving in order to accelerate time to market and to create value added innovations.

CEN/TS 16555-4:2014, Intellectual Property Management (IP): Organizations must consider IPR as a strategic asset that can be linked to competitiveness, especially when considering value creation. Innovation management must consider IP as an enhancer and a tool to increase temporary market advantages and to use it as a knowledge 
management method that can capture information about competitors scientific and technological competences and assets.

CEN/TS 16555-5:2014, Collaboration Management: Innovation management has been evolving towards an open and collaborative model. This TS targets collaboration as a new domain that needs strategic guidance and management processes capable to enable organizations with internal tools to address issues that include "Why", "When", "How" and "With whom".

CEN/TS 16555-6:2014, Creativity Management: Ideas are at the heart of the innovation process. By that reason, it was considered crucial to identify conditions necessary to nurture and develop ideas generation, collection, selection and implementation.

CEN/TS 16555-7:2015, Innovation Management Assessment: Evaluation and assessment of innovation contribution to firms performance, competitiveness and sustainability are powerful instruments. Among other reasons, learning and improvement can illustrate why innovation assessment is gaining relevance at micro and macro levels. Through this TS, organizations can identify which tools can be used, from simple check lists to more complex models as the maturity or benchmarking instruments (Figure 2), and which results can be obtained.

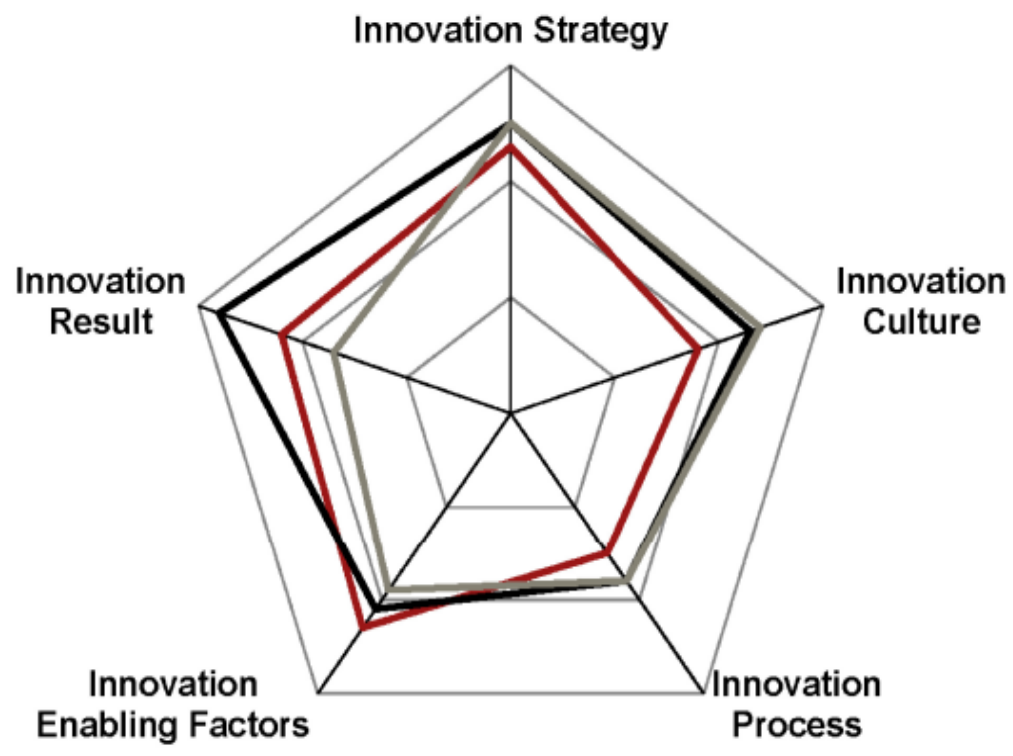

Own organisation $=$ Benchmark Average

Fig. 2. Benchmarking assessment.

Source: CEN. (2015). Innovation Management - Part 7: Innovation Management Assessment (CEN/TS 16555-7:2015). European Committee for Standardization (CEN).

Created in 2013, and involving almost 50 countries, ISO Technical Committee TC 279 placed innovation management standardization at a global level. Its main purpose is to develop, maintain and promote standards contributing to long term competitiveness and 
sustainability, identifying the main elements, or determinants, for innovation management, not only within the organizations but also in its interaction with other players of the ecosystem. It has been recognized the need to develop international innovation management systems standardization documents, following other management systems standardization movements like quality or environment.

As in CEN TC 389, four working groups (WG) were launched to define the IMS (WG1), the terminology (WG2), the tools and methods to support innovation (WG3) and the innovation management assessment (WG4). A common vision, shared by members and consolidated in a set of principles (WG1), highlights the importance of leadership, culture, strategy, openness, adaptability and experimentation for innovation management and its ultimate goal: value creation.

The Portuguese Technical Committee has been participating in those activities, as a mirror committee that proactively promotes the participation of about 30 organizations from the national innovation system.

\section{Concluding Remarks}

Organizations, in spite of its R\&D and innovation profile, should consider innovation management standardization as a learning opportunity and a strategic instrument to target competitiveness enablers and processes.

Innovation Management Standards can be used as management tools enabling organizations to absorb knowledge, to learn from best practices and to apply already tested innovation management approaches and methodologies.

In Portugal, almost 200 companies have already applied innovation management standards and certified its systems according to NP 4457:2007. As indicated previously, advantages exist, including for SME that can access to global, harmonized and state of the art innovation management guidelines in a simple and systematic way. Also, as observed at national level, and as innovation is progressively linked to other management systems, organizations have the possibility to ensure its compatibility with other management systems already in place and to use standards, in a flexible way and for different, and complementary, purposes: certification, self assessment or assessment by any other interested party, contributing to increase the role innovation can play as a driver for organizational success in a context of accelerated change and uncertainty.

Considering innovation management standardization as a knowledge resource, one could expect that public policies support stakeholders in order to accelerate its dissemination and adoption, creating dynamic capabilities to sustain competiveness and value creation. And the challenge is not local or national anymore.

Acknowledgements. The author thanks to the Portuguese CT 169 members, specially Joana dos Guimarães Sá (Committee Member, ISO TC 279, WG 1) for comments and Eduardo Correia (Secretary of CT 169) for revision of an earlier version of this Letter. 


\section{$5 \quad$ References}

Blind, Knut (2013), The Impact of Standardization and Standards on Innovation, NESTA Working Paper 13/15.

Caetano, I. (2017). Innovation, Evaluation and Measurement: Macro-Level and FirmLevel Perspectives. In the Quadruple Innovation Helix Nexus (pp. 173-210). Palgrave Macmillan US.

Caetano, I., \& Sá, J. dos G. (2013). Certificação de sistemas de gestão da investigação, desenvolvimento e inovação. Ingenium, 136 (Julho - Agosto 2013) 36-37.

Caraça, J., Lundvall, B.-Å.\& Mendonça, S. (2009). The changing role of science in the innovation process: From Queen to Cinderella? Technological Forecasting and Social Change. 76(6): p. 861-867

CEN. (2013). Innovation Management - Part 1: Innovation Management System (CEN/TS 16555 1). European Committee for Standardization.

COTEC Portugal (2007), Innovation Scoring Support Manual. Available at: http://www.innovationscoring.org/images/conteudo/Innovation\%20Scoring_EN G.pdf Accessed May 2017.

COTEC Portugal (2010), Guia de Boas Práticas de Gestão de Inovação, Available at: http://www.cotecportugal.pt/images/stories/iniciativas/DSIE/FaseII/guia_boas_p raticas.pdf Accessed May 2017.

European Commission (2008), Towards an increased contribution from standardization to Innovation in Europe, COM (2008)133 final, Brussels

NP 4456:2007. (2007). Management of Research, Development and Innovation (RDI) - Terminology and definitions of RDI activities, IPQ.

NP 4457:2007. (2007). Management of Research, Development and Innovation (RDI) - RDI Management system requirements, IPQ.

NP 4458:2007. (2007). Management of Research, Development and Innovation (RDI) - Requirements for a RDI project, IPQ.

NP 4461:2007. (2007). Management of Research, Development and Innovation (RDI) - Competence and evaluation of RDI management systems auditors and RDI projects auditors, IPQ.

OECD (2005). Oslo Manual: Guidelines for Collecting and Interpreting Innovation Data, 3rd Edition

Swann G.M.P. (2010). The Economics of Standardization: An Update. Innovative Economics Limited Manchester. 